\title{
Hormonal Modulation of Sensorimotor Integration
}

\author{
Nicholas D. DeLong and Michael P. Nusbaum \\ Department of Neuroscience, University of Pennsylvania School of Medicine, Philadelphia, Pennsylvania 19104
}

Neuronal circuits commonly receive simultaneous inputs from descending, ascending, and hormonal systems. Thus far, however, most such inputs have been studied individually to determine their influence on a given circuit. Here, we examine the integrated action of the hormone crustacean cardioactive peptide (CCAP) and the gastropyloric receptor (GPR) proprioceptor neuron on the biphasic gastric mill (chewing) rhythm driven by the projection neuron modulatory commissural neuron 1 (MCN1) in the isolated crab stomatogastric ganglion. In control saline, GPR stimulation selectively prolongs the gastric mill retractor phase, via presynaptic inhibition of MCN1. In the absence of GPR stimulation, CCAP does not alter retraction duration and modestly prolongs protraction. Here, we show, using computational modeling and dynamic-clamp manipulations, that the presence of CCAP weakens or eliminates the GPR effect on the gastric mill rhythm. This CCAP action results from its ability to activate the same modulator-activated conductance $\left(G_{\mathrm{MI}}\right)$ as $\mathrm{MCN} 1$ in the gastric mill circuit neuron lateral gastric (LG). Because GPR prolongs retraction by weakening MCN1 activation of $G_{\mathrm{MI}}$ in LG, the parallel $G_{\mathrm{MI}}$ activation by CCAP reduces the impact of GPR regulation of this conductance. The CCAP-activated $G_{\mathrm{MI}}$ thus counteracts the GPRmediated decrease in the MCN1-activated $G_{\mathrm{MI}}$ in LG and reduces the GPR ability to regulate the gastric mill rhythm. Consequently, although CCAP neither changes retraction duration nor alters GPR inhibition of MCN1, its activation of a modulator-activated conductance in a pivotal downstream circuit neuron enables CCAP to weaken or eliminate sensory regulation of motor circuit output.

\section{Introduction}

Rhythmically active motor circuits generate multiple distinct motor patterns because of descending, ascending, and hormonal inputs (Jing and Weiss, 2005; Marder et al., 2005; Dickinson, 2006; Rossignol et al., 2006; Büschges et al., 2008; Doi and Ramirez, 2008). Despite the fact that parallel inputs to a circuit are likely commonly coactive (Dickinson, 2006; Marder and Bucher, 2007; Doi and Ramirez, 2008; Pearson, 2008), in most cases these inputs have been studied individually. Coactivating parallel inputs will not necessarily result in a simple summation of their individual actions because of circuit interactions and possibly interactions between these inputs (McLean and Sillar, 2004; Beenhakker et al., 2007; Blitz and Nusbaum, 2007; Barrière et al., 2008; Büschges et al., 2008).

We are addressing this issue by studying the influence of hormonal modulation on sensory feedback to a central pattern generator (CPG) circuit, using the isolated stomatogastric nervous system (STNS) of the crab Cancer borealis (Nusbaum and Beenhakker, 2002; Marder and Bucher, 2007). The STNS contains distinct but interacting CPGs whose outputs are regulated by projection neurons, sensory neurons, and hormones (Marder and Bucher, 2007). The gastric mill (chewing) CPG, located in the stomatogastric ganglion (STG), is driven by the projection

Received Nov. 9, 2009; revised Dec. 31, 2009; accepted Jan. 2, 2010.

This work was supported by National Institute of Neurological Disorders and Stroke Grants R37-NS 29436 (M.P.N.) and F31-NS 58013 (N.D.D.). We thank Dawn M. Blitz and Jason C. Rodriguez for helpful discussions and comments on previous versions of this paper.

Correspondence should be addressed to Dr. Michael P. Nusbaum, Department of Neuroscience, University of Pennsylvania School of Medicine, 215 Stemmler Hall, Philadelphia, PA 19104-6074. E-mail: nusbaum@mail.med. upenn.edu.

DOI:10.1523/JNEUROSC1.5533-09.2010

Copyright $\odot 2010$ the authors $\quad 0270-6474 / 10 / 302418-10 \$ 15.00 / 0$ neuron modulatory commissural neuron 1 (MCN1) (Nusbaum et al., 2001). This CPG includes the reciprocally inhibitory protractor phase neuron lateral gastric (LG) and retractor phase neuron interneuron 1 (Int1), plus the STG axon terminals of MCN1 $\left(\mathrm{MCN1}_{\mathrm{STG}}\right)$ (Coleman et al., 1995; Bartos et al., 1999). MCN1 drives this rhythm via slow, peptidergic excitation of LG and fast, GABAergic excitation of Int1 (Wood et al., 2000; Stein et al., 2007). These actions occur during retraction, because LG inhibits $\mathrm{MCN1}_{\mathrm{STG}}$ during protraction (Coleman et al., 1995). MCN1 excites LG by activation of the modulator-activated inward conductance $\left(G_{\mathrm{MI}}\right)$ (DeLong et al., 2009a).

The MCN1-elicited gastric mill rhythm is altered by both the peptide hormone crustacean cardioactive peptide (CCAP) and the gastropyloric receptor (GPR) neuron (Beenhakker et al., 2005; Kirby and Nusbaum, 2007; DeLong et al., 2009a,b). Bathapplied CCAP selectively prolongs protraction, by providing a parallel activation of $G_{\mathrm{MI}}\left(G_{\mathrm{MI}-\mathrm{CCAP}}\right)$ in LG (DeLong et al., 2009a). GPR selectively prolongs retraction by presynaptically inhibiting $\mathrm{MCN}_{\mathrm{STG}}$ and thereby reducing the rate at which MCN1-activated $G_{\mathrm{MI}}\left(G_{\mathrm{MI}-\mathrm{MCN} 1}\right)$ builds up in LG (Beenhakker et al., 2005; DeLong et al., 2009b).

Here, we investigate how CCAP modulates GPR regulation of the MCN1-gastric mill rhythm. Our computational model predicts that adding $G_{\mathrm{MI} \text {-CCAP }}$ to LG is sufficient to weaken GPR regulation of this rhythm, by reducing the impact of the GPRinduced reduction of $G_{\mathrm{MI}-\mathrm{MCN} 1}$ in LG. Supporting this prediction, bath-applied CCAP weakened the GPR effect on this rhythm. Furthermore, dynamic-clamp-injected $G_{\text {MI-CCAP }}$ into LG mimicked this CCAP action, whereas dynamic-clamp subtraction of $G_{\mathrm{MI}-\mathrm{CCAP}}$ in LG during CCAP bath application eliminated the peptide regulation of this GPR action. These results illustrate that modulation of sensorimotor integration can result 
from a parallel activation of an ionic current in a downstream circuit neuron, without a direct action on either the sensory neuron or its synaptic target.

\section{Materials and Methods}

Animals. Male Jonah crabs (C. borealis) were obtained from commercial suppliers (Yankee Lobster; Marine Biological Laboratory). Crabs were housed in commercial tanks containing recirculating, aerated, artificial seawater $\left(10-12^{\circ} \mathrm{C}\right)$. Before dissection, the crabs were cold-anesthetized by packing them in ice for at least $30 \mathrm{~min}$. The foregut was then removed and maintained in chilled physiological saline while the STNS was dissected from it and pinned down in a saline-filled silicone elastomer-lined Petri dish (Sylgard 184; KR Anderson).

Solutions. The isolated STNS was maintained in C. borealis saline containing the following (in mM): $439 \mathrm{NaCl}, 26 \mathrm{MgCl}_{2}, 13 \mathrm{CaCl}_{2}, 11 \mathrm{KCl}, 10$ Trizma base, and 5 maleic acid, $\mathrm{pH}$ 7.4-7.6. During experimentation, the preparation was continuously superfused $\left(7-12 \mathrm{ml} / \mathrm{min} ; 10-12^{\circ} \mathrm{C}\right)$ with C. borealis saline via a switching manifold, to enable fast solution changes. CCAP (Bachem) was diluted from stock solution into saline immediately before use.

Electrophysiology. All experiments were conducted using the isolated STNS from which the CoGs were removed by transecting the superior (sons) and inferior oesophageal nerves (ions) (see Fig. 1A). Intracellular and extracellular recordings of gastric mill neurons were made using routine methods for the STNS (Beenhakker and Nusbaum, 2004). Sharp glass microelectrodes (15-30 M $\Omega$ ), filled with $0.6 \mathrm{M} \mathrm{K}_{2} \mathrm{SO}_{4}$ plus $10 \mathrm{~mm}$ $\mathrm{KCl}$, were used for intracellular recordings. Intracellular recordings were made with Axoclamp 2 amplifiers (Molecular Devices), and intracellular current-clamp injections were performed in single electrode discontinuous current-clamp (DCC) mode with sampling rates of $2-5 \mathrm{kHz}$. To facilitate intracellular recordings, the STG was desheathed and visualized with light transmitted through a dark-field condenser (Nikon).

Each extracellular nerve recording was made using a pair of stainlesssteel wire electrodes (reference and recording), the ends of which were pressed into the Sylgard-coated dish. A differential AC amplifier (model 1700; A-M Systems) amplified the voltage difference between the reference wire, placed in the bath, and the recording wire, placed near an individual nerve and isolated from the bath by petroleum jelly (Vaseline; Lab Safety Supply). This signal was then further amplified and filtered (model 410 amplifier; Brownlee Precision). Extracellular nerve stimulation was accomplished by placing the pair of wires used to record nerve activity into a stimulus isolation unit (SIU 5; Astro-Med/Grass Instruments) that was connected to a stimulator (model S88; Astro-Med/Grass Instruments).

To elicit the gastric mill rhythm in the isolated STG, MCN1 was selectively activated by tonic extracellular stimulation of one or both of the transected ions $(10-15 \mathrm{~Hz}$ ), on the STG side of the transection (see Fig. 1) (Coleman et al., 1995; Bartos and Nusbaum, 1997). The gastric mill protractor phase is defined as the duration of the LG burst, whereas the retractor phase is defined as the duration of the LG interburst/Int1 burst. Individual STNS neurons were identified by their axonal pathways, activity patterns, and interactions with other neurons (Weimann et al., 1991; Blitz et al., 1999; Beenhakker and Nusbaum, 2004).

GPR was selectively activated by extracellular stimulation of the gastropyloric nerve ( $g p n$ ) (Katz et al., 1989; Beenhakker et al., 2005). Unless otherwise indicated, we stimulated GPR during the retractor phase of the gastric mill rhythm, to mimic its likely in vivo activity pattern (Katz et al., 1989), although tonic GPR stimulation has the same effect because GPR does not alter the gastric mill protractor phase (DeLong et al., 2009b). We used a stimulation frequency $(5-15 \mathrm{~Hz})$ within the frequency range exhibited by GPR in response to stretch of the muscles in which its dendrites are embedded (Katz et al., 1989; Birmingham et al., 1999). GPR stimulation was performed manually, by turning on the stimulator at the start of the retractor phase and terminating the stimulation before or immediately after the end of the retractor phase (i.e., LG burst onset). These stimulations were typically longer in duration than the control retractor phase duration because GPR stimulation prolongs this phase of the gastric mill rhythm (Beenhakker et al., 2005; DeLong et al., 2009b). In some experiments, we terminated GPR stimulation before the end of the retractor phase to ensure the continuation of the gastric mill rhythm. This approach was necessary because we used standardized MCN1 and GPR stimulation rates, and, under this condition, the balance between MCN1 excitation of LG and the GPR inhibition of $\mathrm{MCN1}_{\mathrm{STG}}$ sometimes favored the latter action. In those cases, LG could not escape from Int1 inhibition until GPR stimulation was terminated (Beenhakker et al., 2005; DeLong et al., 2009b). During these latter circumstances, we used an approximately threefold increase in retraction duration $(30 \mathrm{~s})$ as our cutoff duration, at which point we terminated the GPR stimulation.

Dynamic clamp. We used the dynamic clamp to inject an artificial version of a voltage-dependent ionic current $\left(I_{\mathrm{MI}}\right)$ into the LG neuron (Sharp et al., 1993; Bartos et al., 1999; Prinz et al., 2004; Beenhakker et al., 2005; DeLong et al., 2009a). The dynamic-clamp software uses the intracellularly recorded membrane potential of a biological neuron to calculate an artificial current $\left(I_{\mathrm{dyn}}\right)$ using a conductance $\left[g_{\mathrm{dyn}}(t)\right]$ that is numerically computed, as well as a predetermined reversal potential $\left(E_{\text {rev }}\right)$. The artificial current is computed in real time, updated in each time step $(0.2 \mathrm{~ms})$ according to the new values of recorded membrane potential, and injected back into the biological neuron.

For these experiments, we used a version of the dynamic clamp developed in the Nadim Laboratory (Rutgers University, Newark, NJ) (available at http://stg.rutgers.edu/software/) to run on a personal computer (PC) running Windows XP and a NI PCI-6070-E data acquisition board (National Instruments). As above, all dynamic-clamp current injections were performed while recording in single-electrode, DCC mode (sampling rates, $2-5 \mathrm{kHz}$ ).

Data analysis. Data analysis was facilitated by a custom-written program (The Crab Analyzer) for Spike2 (Cambridge Electronic Design) that determines the activity levels and burst relationships of individual neurons (freely available at http://www.uni-ulm.de/ wstein/ spike2/index.html). Unless otherwise stated, each data point in a data set was derived by determining the mean of 7-10 consecutive gastric milltimed LG bursts, except during GPR stimulations when the average was taken across the duration of the GPR stimulation (1-5 cycles). In all experiments, the burst duration was defined as the duration (in seconds) between the onset of the first and last action potential in an impulse burst.

Data were collected onto a chart recorder (models MT 95000 and Everest; Astro-Med) and simultaneously onto a PC using data acquisition/analysis tools (Spike2; digitized at $\sim 5 \mathrm{kHz}$ ). Figures were made from Spike2 files incorporated into Adobe Illustrator (Adobe). Statistical analyses were performed with Microsoft Excel (Microsoft) and SigmaStat 3.0 (SPSS). Comparisons of phase durations were made using the paired Student's $t$ test unless otherwise indicated. For one data set, the repeatedmeasures ANOVA (RM-ANOVA) followed by the Student-NewmanKeuls (SNK) post hoc test was used to verify that, as previously shown, CCAP superfusion had no effect on the baseline retraction duration (DeLong et al., 2009a). In all experiments, the effect of each manipulation was reversible, and there was no significant difference between the premanipulation and postmanipulation groups. Data are expressed as the mean $\pm \mathrm{SE}$.

Computational model. To study the hormonal CCAP influence on the GPR regulation of the gastric mill rhythm, we modified an existing conductance-based computational model of the gastric mill circuit (Nadim et al., 1998; Beenhakker et al., 2005; DeLong et al., 2009a). Specifically, we retained from the previous versions of this model the LG, Int 1, and MCN1 neurons having multiple compartments separated by an axial resistance, with each compartment possessing intrinsic and/or synaptic conductances (see Fig. $2 \mathrm{~A}$ ). We combined our previously published models that included GPR (Beenhakker et al., 2005) and CCAP (DeLong et al., 2009a), but we did not add or modify any synaptic or intrinsic conductances beyond those previously published (Tables 1,2).

As published previously (Beenhakker et al., 2005), to model the GPR neuron we used a single-compartment cell with a passive leak current plus Hodgkin-Huxley-like voltage-dependent inward and outward currents to enable action potential generation. Consistent with physiological measurements (Beenhakker et al., 2005), this model neuron made an inhibitory synaptic connection onto a distal compartment of the MCN1 axon terminals (t0 compartment) (see Fig. 2A) (Nadim et al., 1998). To mimic the cumulative action of repeated GPR stimulations, the GPR 
Table 1. GPR model parameters

\begin{tabular}{|c|c|c|c|c|c|c|c|c|}
\hline & $G_{\max }(n S)$ & $E_{\mathrm{rev}}(\mathrm{mV})$ & $p$ & $q$ & $m_{\text {inf }}$ & $m_{\tau}$ & $h_{\text {inf }}$ & $h_{\tau}$ \\
\hline Synapses & & & & & 1 & 4000 & & \\
\hline $\begin{array}{c}\text { GPR-MCN1 } \\
\text { GPR intrinsic currents }\end{array}$ & 40 & -80 & - & - & $\frac{1}{1+e^{-(V+60)}}$ & $2000+\frac{7000}{1+e^{V+60}}$ & - & - \\
\hline Leak & 3 & -68 & $\mathrm{~N} / \mathrm{A}$ & $\mathrm{N} / \mathrm{A}$ & $\mathrm{N} / \mathrm{A}$ & $\mathrm{N} / \mathrm{A}$ & $\mathrm{N} / \mathrm{A}$ & $\mathrm{N} / \mathrm{A}$ \\
\hline $\mathrm{Na}$ & 120 & 50 & 3 & 1 & $\frac{1}{1+e^{-5(V+62)}}$ & Inst & $\frac{1}{1+e^{5(V+64)}}$ & $1+\frac{5}{1+e^{-0.24(V+64)}}$ \\
\hline K & 36 & -77.5 & 4 & $\mathrm{~N} / \mathrm{A}$ & $\frac{1}{1+e^{-5(V+54)}}$ & $8+\frac{20}{1+e^{0.24(V+54)}}$ & $\mathrm{N} / \mathrm{A}$ & $\mathrm{N} / \mathrm{A}$ \\
\hline
\end{tabular}

Parameters used to incorporate GPR into an existing model of the gastric mill rhythm (Nadim et al., 1998; Beenhakker et al., 2005). GPR was modeled as a single-compartment cell with active and passive properties, and the slowly activating GPR-MCN1 synapse was added. Abbreviations: $E_{\text {rev }}$, reversal potential; $G_{\max }$, conductance value at maximum activation; $h_{\text {inf }}$, steady-state inactivation curve; $h_{\tau}$, inactivation time constant; Inst, instantaneous time constant; $m_{\text {inf }}$, steady-state activation curve; $m_{\tau}$, activation time constant; N/A, not relevant to computation; $p$, integer power of the activation variable $m ; q$, integer power of the inactivation variable $h$. Parameter names are derived from the nomenclature used in the Network modeling software, which was used to perform all simulations (http://stg.rutgers.edu/software/network.htm).

Table 2. Gastric mill rhythm model parameters for $I_{\text {MI-CCAP }}$

\begin{tabular}{lllllll}
\hline Current & $G_{\max }$ & $E_{\text {rev }}$ & $m_{\text {inf }}$ & $m_{\tau}$ & $m_{\text {postinf }}$ & $m_{\text {post }-\tau}$ \\
\hline$I_{\text {MI-CCAP }}$ & 0.2 & 0 & $\frac{1}{1+e^{-0.1\left(V_{16}+50\right)}}$ & 50 & N/A & N/A \\
\hline
\end{tabular}

The values used for $I_{\text {MI-CCAP }}$ in the computational model of the MCN1-elicited gastric mill rhythm (DeLong et al., 2009a). Abbreviations: $m_{\text {postinf }}$ Steady-state activation curve for the postsynaptic voltage dependence; $m_{\text {post- }-\tau^{\prime}}$ activation time constant for the postsynaptic voltage dependence. See Table 1 for all other abbreviations. Parameter names are derived from the nomenclature used in the Network modeling software, which was used to perform all simulations (http://stg.rutgers.edu/software/network.htm).

synapse onto MCN1 was modeled as a slowly activating, slowly deactivating current (Beenhakker et al., 2005). The conductances and other parameters of these currents were chosen to mimic the behavior of the gastric mill circuit in the presence of GPR stimulation (Table 1).

Additionally, as published previously (DeLong et al., 2009a), we added to the LG neuron dendrite compartment an intrinsic (i.e., nonsynaptically activated) current $\left(I_{\mathrm{MI}-\mathrm{CCAP}}\right)$ with the same voltage dependence as $I_{\text {MI-MCN1 }}$ (Table 2) to mimic the effects of CCAP bath application on the biological system. This approach was based on the fact that CCAP and MCN1-released C. borealis tachykinin-related peptide Ia (CabTRP Ia) both excite LG by activating $I_{\mathrm{MI}}$ in this neuron (DeLong et al., 2009a).

Simulations were performed on a PC with Windows XP. We used the Network simulation software developed in the Nadim laboratory (http://stg.rutgers.edu/software/network.htm), which was run using the freely available CYGWIN Linux emulation software package. We used a fourth-order Runge-Kutta numerical integration method with time steps of 0.05 and $0.01 \mathrm{~ms}$. Results were visualized by plotting outputted data points using the freely available Gnuplot software package (www.gnuplot.info).

It is important to note that the $I_{\mathrm{MI}}$ presentation in the model and dynamic-clamp figures represents different conventions. Specifically, the model output directly reports actual current flow in the model neuron and so uses the standard voltage-clamp convention. In contrast, the dynamic-clamp output represents the current injected into the neuron and hence uses the standard current-clamp convention. Consequently, $I_{\mathrm{MI}}$ is represented as an inward (downward trajectory) current in the model output figures but is represented as a depolarizing (upward trajectory) current injection in the dynamic-clamp output figures.

\section{Results}

CCAP and GPR prolong the gastric mill protractor and retractor phases, respectively, by regulating $G_{M I}$ in the LG neuron

When manipulated separately, both CCAP and GPR influence the MCN1-elicited gastric mill rhythm (Fig. $1 B-D$ ). CCAP gains access to the STG as a circulating hormone (Christie et al., 1995; Li et al., 2003; Chen et al., 2009). Bath-applied CCAP (threshold, $10^{-10} \mathrm{M}$ ) causes a modest but consistent prolongation of the protractor phase during the MCN1-gastric mill rhythm (Fig. 1 B) (Kirby and Nusbaum, 2007). This CCAP action results from its convergent activation of the modulator-activated inward con- ductance $G_{\mathrm{MI}}$ in LG with that of MCN1-released CabTRP Ia (DeLong et al., 2009a). $G_{\mathrm{MI}-\mathrm{CCAP}}$ sums with $G_{\mathrm{MI}-\mathrm{MCN} 1}$ in LG, but they have different activation and deactivation trajectories during protraction because only $G_{\mathrm{MI}-\mathrm{MCN} 1}$ is synaptically regulated by LG. Consequently, during protraction, $G_{\mathrm{MI}-\mathrm{CCAP}}$ maintains a relatively constant amplitude while $G_{\mathrm{MI}-\mathrm{MCN} 1}$ decays because of the inhibitory synapse from LG to $\mathrm{MCN1}_{\mathrm{STG}}$ (Figs. $1 C$, 2). The maintained $G_{\mathrm{MI}-\mathrm{CCAP}}$ amplitude sums with the decaying $G_{\mathrm{MI}-\mathrm{MCN} 1}$ to keep LG suprathreshold for a longer duration, prolonging its burst (DeLong et al., 2009a). By summing with $G_{\mathrm{MI}-\mathrm{MCN} 1}$, $G_{\mathrm{MI}-\mathrm{CCAP}}$ also acts to prevent a change in the gastric mill retractor phase duration (DeLong et al., 2009a). This unchanged retraction duration occurs because the $G_{\mathrm{MI}-\mathrm{CCAP}}$ compensates for a reduced $G_{\mathrm{MI}-\mathrm{MCN} 1}$ amplitude during retraction, which results from the $G_{\mathrm{MI}-\mathrm{MCN} 1}$ decaying to a lower level during the prolonged protraction phase (DeLong et al., 2009a).

GPR is a bilaterally symmetric pair of muscle stretch-sensitive sensory neurons whose dendrites arborize in gastric mill protractor muscles (Katz et al., 1989). Hence, the GPRs are activated during retraction, when the protractor muscles are stretched (Katz et al., 1989; Katz and Harris-Warrick, 1989). GPR selectively prolongs the gastric mill retractor phase by its presynaptic inhibition of $\mathrm{MCN} 1_{\mathrm{STG}}$ (Fig. 1C,D) (Beenhakker et al., 2005; DeLong et al., 2009b). Mechanistically, this GPR action appears to reduce the rate of CabTRP Ia release from $\mathrm{MCN1}$, which slows the $\mathrm{MCN1}$ activation of $G_{\mathrm{MI}-\mathrm{MCN} 1}$ in LG (Beenhakker et al., 2005; DeLong et al., 2009b). This GPR action occurs without causing a parallel alteration in the MCN1 GABAergic excitation of Int1 (DeLong et al., 2009b). Consequently, GPR prolongs retraction by slowing the buildup of $G_{\mathrm{MI}-\mathrm{MCN} 1}$ in LG and hence slowing the ability of LG to escape from Int1 inhibition and reach burst threshold (Figs. 1D, 2).

\section{CCAP gates the GPR regulation of the gastric mill rhythm in a computational model}

We investigated whether the presence of CCAP influenced the ability of GPR to regulate the gastric mill rhythm. We assessed this possibility because GPR regulates the gastric mill rhythm by influencing the ability of MCN1 to activate $G_{\mathrm{MI}}$ in LG, and CCAP directly activates $G_{\mathrm{MI}}$ in LG. To this end, we combined two pre- 


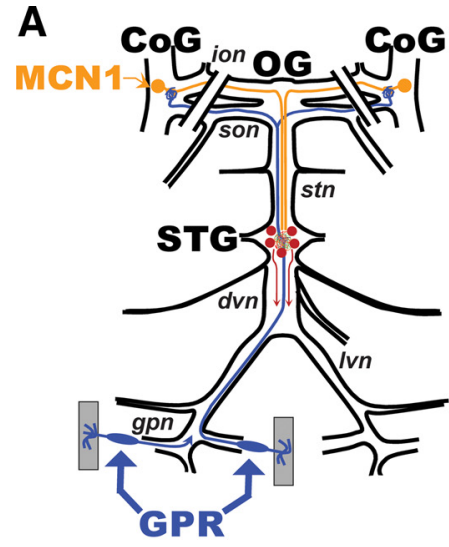

B
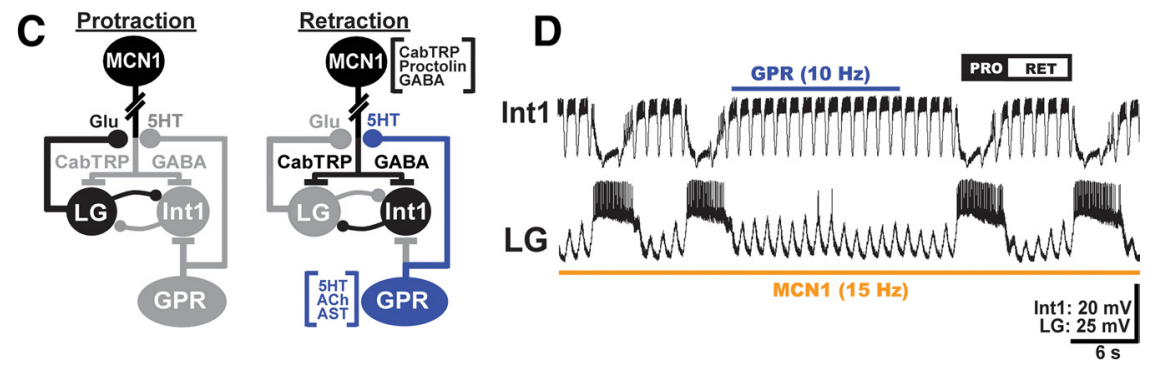

Figure 1. Schematics of the isolated STNS and the MCN1-elicited gastric mill circuit, as well as its regulation by CCAP and GPR $A$, In each CoG, there is a single copy of the projection neuron MCN1, which projects an axon through the ion and stn nerves to the STG. Each GPR projects an axon through the /vn and dvn nerves to arborize in the STG and continues through the stn and son nerves to innervate each COG. The paired diagonal bars through the sons and ions represent the transection of these nerves at the start of each experiment. The gray rectangles represent protractor muscles in which the GPR dendrites arborize. These muscles were removed for the experiments in this paper. Abbreviations: Ganglia: $\mathrm{COG}$, commissural ganglion; $\mathrm{OG}$, oesophageal ganglion. Nerves: $d v n$, dorsal ventricular nerve; Ivn, lateral ventricular nerve; stn, stomatogastric nerve. B, As shown by Kirby and Nusbaum (2007), bath-applied CCAP selectively prolongs the protractor phase of the MCN1-elicited gastric mill rhythm. Note that CCAP did not activate the gastric mill rhythm before MCN1 stimulation. Protraction (PRO) phase is represented by the LG protractor neuron activity. Retraction (RET) phase is represented by the dorsal gastric (DG) retractor neuron activity. The bar on top of second LG burst in each panel represents the $L G$ burst duration in saline, to show that the $L G$ burst is prolonged by CCAP. This panel was reproduced from the study by DeLong et al. (2009a). C, Gastric mill CPG circuit schematics during each phase of the gastric mill rhythm. The paired diagonal bars through MCN1 axon represent additional distance between $\mathrm{C} O \mathrm{G}$ and STG. All synapses shown are located in the STG. The gray somata and synapses represent neurons/synapses that are inactive during the indicated phase of the gastric mill rhythm. Synapses drawn on somata or axons actually occur on small branches in the STG neuropil. Transmitters in brackets next to MCN1 and GPR somata are their identified cotransmitters. Note that MCN1 uses only CabTRP la to excite LG and only GABA to excite

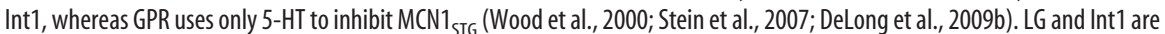
both glutamatergic (Marder, 1987; Saideman et al., 2007a). Transmitter abbreviations: 5-HT, 5-hydroxytryptamine (serotonin); Glu, glutamate. Symbols: Filled circles, Synaptic inhibition; T-bars, synaptic excitation. D, GPR stimulation selectively prolongs the gastric mill retractor phase. Note that the duration of the retractor phase during GPR stimulation is longer than the same phase in the cycles immediately before and after GPR stimulation (Beenhakker et al., 2005). The fast rhythmic action potential bursts in Int1 and the associated fast rhythmic subthreshold LG oscillations represent the influence of the pyloric circuit on the gastric mill CPG (Bartos et al., 1999). The rhythmic subthreshold depolarizations in $L G$ result from the rhythmic removal of Int1-mediated inhibition and the consequent unmasking of MCN1-mediated excitation. $A, C$, and $D$ are reproduced from the study by DeLong et al. (2009b).

viously published versions of our computational model of the MCN1-gastric mill circuit. Specifically, we modified our existing model of the gastric mill CPG plus GPR (Beenhakker et al., 2005; DeLong et al., 2009b) by adding $G_{\text {MI-CCAP }}$ to LG, using previously published parameters (Tables 1, 2; Fig. 2A) (DeLong et al., 2009a). As shown previously, in the version of the model in which $G_{\text {MI-CCAP }}$ was absent from LG, GPR stimulation prolonged the retractor phase (pre-GPR, $7.5 \mathrm{~s}$; during GPR, $34.4 \mathrm{~s}$ ) without altering the protractor phase (pre-GPR, $7.7 \mathrm{~s}$; during GPR, 7.4 s) (Fig. 2A) (Beenhakker et al., 2005).

Adding $G_{\text {MI-CCAP }}$ to LG in our model, in the absence of GPR activation, modestly prolonged the protractor phase (control, $7.7 \mathrm{~s}$; CCAP, $10.7 \mathrm{~s}$ ) without altering the retractor phase duration (control, $7.5 \mathrm{~s}$; CCAP, $7.1 \mathrm{~s}$ ), as occurs in the biological STG (Fig.
2B) (Kirby and Nusbaum, 2007). When GPR was stimulated while $G_{\text {MI-CCAP }}$ was present in LG, the GPR prolongation of retraction was reduced by $>10$-fold, from $>400$ to $\sim 40 \%$ of the control value (preGPR, 7.1 s; during GPR, 10.0 s), whereas the protractor phase duration remained unchanged (pre-GPR, 10.7 s; during GPR, 10.6 s) (Fig. 2C).

The apparent reason for the weakened GPR effect in the model that included $G_{\text {MI-CCAP }}$ in LG was that the addition of this conductance provided an alternative source of $G_{\mathrm{MI}}$ that was not subject to GPR regulation (Figs. $2 C, 3$ ). As stated above, GPR regulates $G_{\mathrm{MI}-\mathrm{MCN} 1}$ in LG by inhibiting $\mathrm{MCN}_{\mathrm{STG}}$ (Beenhakker et al., 2005; DeLong et al., 2009b), but it has no influence on $G_{\mathrm{MI}-\mathrm{CCAP}}$ in LG. Despite this distinction in their synaptic regulation, when both $G_{\mathrm{MI}}$ components were present, they summed, and, hence, so did the resulting $I_{\mathrm{MI}-\mathrm{MCN} 1}$ and $I_{\mathrm{MI}-\mathrm{CCAP}}$ (DeLong et al., 2009a). For example, in the absence of GPR stimulation, the total maximal $I_{\mathrm{MI}}$ amplitude in LG, which occurred during the pyloric rhythm-timed depolarization immediately preceding LG burst onset, was changed by $<5 \%$ by the presence of CCAP (CCAP absent, -21.2 pA; CCAP present, $-20.2 \mathrm{pA})$. Thus, $I_{\mathrm{MI}-\mathrm{MCN} 1}$ and $I_{\mathrm{MI}-\mathrm{CCAP}}$ summed to the same level as $I_{\mathrm{MI}}$ MCN1 in the absence of CCAP (DeLong et al., 2009a).

The fact that $I_{\mathrm{MI}-\mathrm{MCN} 1}$ and $I_{\mathrm{MI}-\mathrm{CCAP}}$ summed suggested that, in the presence of CCAP, the fraction of the total $I_{\mathrm{MI}}$ influenced by GPR would be smaller, and, hence, GPR would have less impact on the ability of this current to depolarize LG and enable it to reach burst threshold. Supporting this hypothesis, in our model the GPR stimulation in the presence of CCAP delayed LG burst onset only slightly relative to the preceding and subsequent $\mathrm{cy}$ cles (Fig. 2C), and the maximal $I_{\mathrm{MI}}$ amplitude immediately before LG burst onset $(-19.5 \mathrm{pA})$ was similar to cycles in which GPR was not stimulated $(-20.2$ $\mathrm{nA}$ ). This maximal $I_{\mathrm{MI}}$ was the summed result of its activation by MCN1 plus CCAP $\left(I_{\mathrm{MI}-\mathrm{MCN} 1},-16.5 \mathrm{pA} ; I_{\mathrm{MI}-\mathrm{CCAP}},-3.0 \mathrm{pA}\right)$.

The corollary to the preceding hypothesis is that, during GPR stimulation, at any given time point during the buildup of $I_{\mathrm{MI}}$ during retraction the maximal total $I_{\mathrm{MI}}$ amplitude should be larger in the presence of CCAP. Indeed, whereas the maximal $I_{\mathrm{MI}}$ was $-19.5 \mathrm{nA}$ at the end of retraction ( $10 \mathrm{~s}$ after retraction onset) during GPR stimulation in the presence of CCAP, when measured during GPR stimulation in the absence of CCAP at the same time point its amplitude (contributed entirely by $I_{\mathrm{MI}-\mathrm{MCN1}}$ ) was smaller $(-17.2 \mathrm{pA})$. Additionally, this amplitude was smaller than the maximal $I_{\mathrm{MI}}$ needed for LG to reach burst threshold. Consequently, under these conditions, LG burst onset did not occur for another $\sim 25 \mathrm{~s}$ (Figs. 2, 3). 
These events are more explicitly compared in Figure 3, which presents the $G_{\mathrm{MI}}$ levels during one model gastric mill cycle in which GPR was stimulated, in the absence versus presence of $G_{\text {MI-CCAP. The }}$ total maximal $G_{\mathrm{MI}}$ grew at a faster rate in the presence of $G_{\mathrm{MI}-\mathrm{CCAP}}$. Hence, similar to what was observed for current amplitudes, when GPR was stimulated in the absence of CCAP and the total maximal conductance $\left(G_{\mathrm{MI}}\right)$ was assayed $10 \mathrm{~s}$ after the start of retraction, there was insufficient $G_{\mathrm{MI}}$ for LG to reach burst threshold (Fig. 3A). In contrast, with $G_{\mathrm{MI}-\mathrm{CCAP}}$ present, the LG burst was initiated after $10 \mathrm{~s}$ of retraction (Fig. $3 B)$. Thus, the presence of the additional, GPR-independent $G_{\text {MI-CCAP }}$ reduced the time needed for $G_{\mathrm{MI}}$ to bring LG to burst threshold, and thereby reduced the effectiveness of GPR relative to when CCAP was absent (Fig. 3C). This result predicted, therefore, that in the biological preparation CCAP would reduce the ability of GPR to prolong the gastric mill retractor phase.

\section{CCAP modulates the GPR influence on} the biological gastric mill rhythm

To test the prediction of the above modeling study, we determined whether CCAP superfusion in the biological preparation comparably modulated the GPR actions on the MCN1-elicited gastric mill rhythm. Specifically, we compared the gastric mill rhythm response to GPR stimulation in control (saline) conditions and in the presence of superfused CCAP.

As proof of principle, we superfused a relatively high CCAP concentration $\left(10^{-7}\right.$ M) and found that it consistently eliminated the GPR prolongation of the gastric mill retractor phase (Fig. 4A). In normal saline, GPR stimulation $(5 \mathrm{~Hz})$ during each retractor phase prolonged retraction (pre-GPR, $7.1 \pm 1.0 \mathrm{~s}$; during GPR, $20.6 \pm 3.5 \mathrm{~s} ; n=8$; RMANOVA, SNK post hoc test, $p<0.001$ ) without altering the protractor phase duration (pre-GPR, $5.1 \pm 0.8 \mathrm{~s}$; during GPR, $5.2 \pm$ $0.4 s ; n=8$; RM-ANOVA, SNK post hoc test, $p=0.71$ ) (Fig. $4 A$ ). In contrast, during CCAP superfusion, the same GPR stimulation protocol did not alter either retraction duration (pre-GPR, 7.1 \pm $1.3 \mathrm{~s}$; during GPR, $9.9 \pm 1.7 \mathrm{~s} ; n=8$; RM-ANOVA, SNK post hoc test, $p=0.32$ ) or protraction duration (pre-GPR, $7.1 \pm 0.6 \mathrm{~s}$; during GPR, $7.0 \pm 0.8 s ; n=8$; RM-ANOVA, SNK post hoc test, $p=0.97$ ) (Fig. 4A). This CCAP effect resulted from its influence on the GPR action and not on the control duration of the retractor phase, because the retraction duration was the same in saline and CCAP in the absence of GPR stimulation (RM-ANOVA, SNK post hoc test, $p=0.99$ ) (DeLong et al., 2009a), whereas the retraction duration during GPR stimulation was longer in saline than in the presence of CCAP (RM-ANOVA, SNK post hoc test, $p<0.001$ ).

Superfusing a lower CCAP concentration $\left(10^{-9} \mathrm{M}\right)$, within the concentration range likely present in the hemolymph in vivo (Phlip- pen et al., 2000) [Kirby and Nusbaum (2007), their Discussion], also weakened the GPR action on the MCN1-gastric mill rhythm. As occurred in the above experiments using the higher CCAP concentration, in these preparations GPR stimulation prolonged retraction during saline superfusion (pre-GPR, $8.9 \pm 1.3$ s; during GPR, $20.1 \pm$ $4.4 \mathrm{~s} ; n=4 ; p<0.05)$ but not during $\operatorname{CCAP}\left(10^{-9} \mathrm{M}\right)$ application (pre-GPR, $8.3 \pm 1.3 \mathrm{~s}$; during GPR, $9.8 \pm 1.6 \mathrm{~s} ; n=4 ; p=0.25$ ). Also as above, protraction duration was not altered by GPR stimulation either during saline $(n=4 ; p=0.19)$ or $\operatorname{CCAP}\left(10^{-9} \mathrm{M}\right)$ superfusion $(n=4 ; p=0.22)$. These results were consistent with our model prediction that CCAP gates out the GPR effect on the MCN1-elicited gastric mill rhythm.

To further assess the effectiveness of this CCAP gating effect, we tested whether CCAP also suppressed the gastric mill rhythm response to stimulating GPR at a faster frequency $(10-15 \mathrm{~Hz})$. Specifically, under control conditions, faster frequency stimulation of GPR consistently maintained the retractor phase until after the stimulation was terminated (30 s: $n=3$ of 3 ) (Fig. $4 B$ ). 
A MCN1 Only

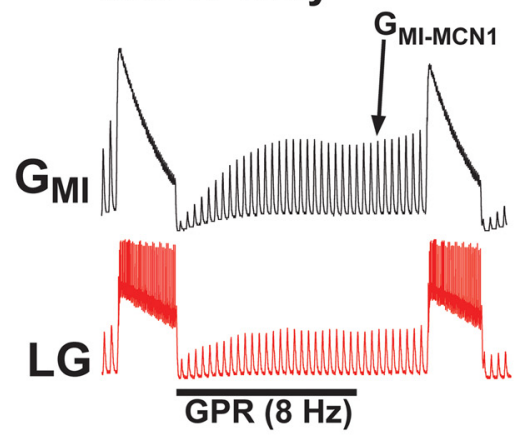

B $\quad$ MCN1 + CCAP

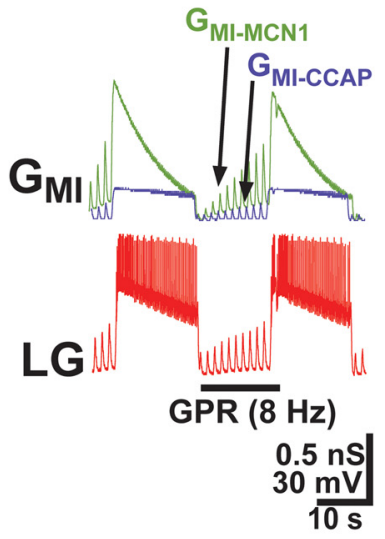

C Overlay A+B (retraction)

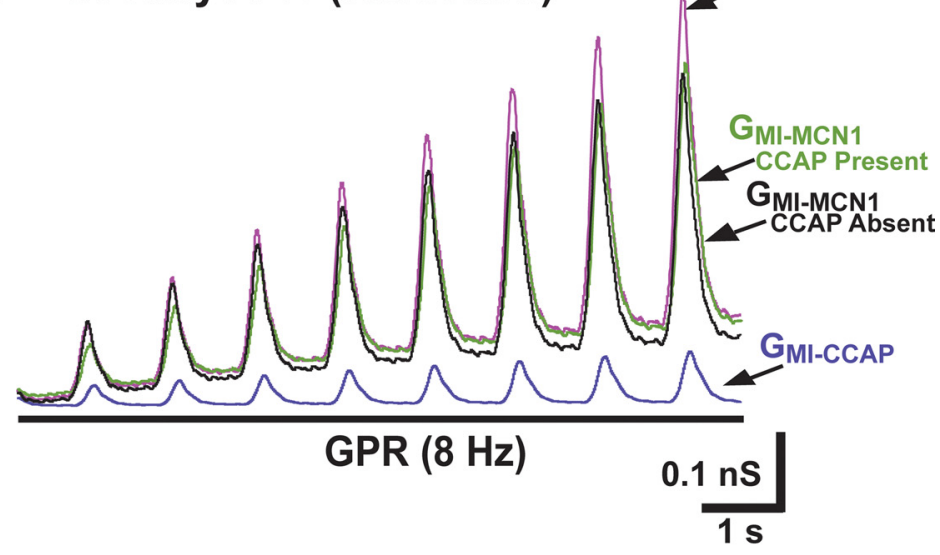

Figure 3. The altered $G_{M I}$ dynamics in the $L G$ neuron when CCAP is present reduces the ability of $G P R$ to prolong the gastric mill retractor phase in a computational model. $A$, During the control gastric mill rhythm, $G_{M I}$ in $L G$ was entirely attributable to input from MCN1 $\left(G_{\mathrm{MI}-\mathrm{MCN1}}\right)$. Under these conditions, GPR stimulation prolonged the retractor phase (Fig. $2 B$ ) by reducing the rate of buildup of $G_{M I-M C N 1}$ caused by the GPR presynaptic inhibition of MCN1 (Beenhakker et al., 2005; DeLong et al., 2009b). $B$, When CCAP was present, $G_{\mathrm{MI}}$ consisted of the summed components contributed by $\mathrm{MCN} 1\left(G_{\mathrm{MI}-\mathrm{MCN} 1}\right)$ and $C \mathrm{CAP}\left(G_{\mathrm{MI}-\mathrm{CCAP}}\right)$. Under this condition, GPR stimulation was less effective in prolonging retraction. $C$, The presence of CCAP during MCN1 stimulation produced a summed maximal $G_{M I}$ in $L$ G during the retractor phase that grew at a faster rate than when $G_{M I}$ was entirely contributed by MCN1. The $G_{M I}$ traces from $\boldsymbol{A}$ and $\boldsymbol{B}$ are overlaid, for durations that span the first $\sim 10 \mathrm{~s}$ of the retractor phase during GPR stimulation. With CCAP both present and absent, the amplitude of $G_{M 1-M C N 1}$ grew steadily during retraction. However, the presence of CCAP produced a summed maximal $G_{M I}$ that grew at a faster rate, because it was additionally composed of the GPR-independent $G_{\text {MI-CCAP. }}$. Hence, the summed maximal $G_{\text {MI }}$ in the presence of CCAP enabled LG to attain burst threshold sooner.

In contrast, in the presence of CCAP $\left(10^{-7} \mathrm{M}\right)$ the LG neuron consistently escaped during the faster frequency GPR stimulation and fired a burst before the $30 \mathrm{~s}$ of GPR stimulation was completed ( $n=3$ of 3 ) (Fig. $4 B$ ), as also occurred during $5 \mathrm{~Hz} \mathrm{GPR}$ stimulation (Fig. 4A). Overall, CCAP gated out the influence of this faster frequency GPR stimulation $(n=3$; RM-ANOVA, SNK post hoc test, GPR vs pre-GPR in CCAP, $p=0.13$ ), as it had done to the 5 $\mathrm{Hz}$ GPR stimulation, although in two of these three preparations the effect of the faster frequency GPR stimulation was reduced but not eliminated (Fig. $4 \mathrm{~B}$ ). As was the case for the $5 \mathrm{~Hz}$ stimulation studies reported above (Fig. $4 A$ ), this CCAP action resulted from its ability to limit the retractor phase duration during the faster frequency GPR stimulation relative to the duration that occurred during saline superfusion (RM-ANOVA, SNK post hoc test, $p<0.005$ ). This conclusion was supported by the fact that CCAP did not alter retraction duration relative to saline superfusion in the absence of GPR stimulation (RM-ANOVA, SNK post hoc test, $p=0.90$ ) (Fig. $4 B$ ).

The above experiments were performed by stimulating GPR during the retractor phase to mimic the likely GPR in vivo activity pat- tern (Katz et al., 1989). However, because CCAP reduced the ability of GPR to prolong retraction, the total time during which GPR was stimulated was less in CCAP than in control conditions. To eliminate this potential confound, we also tested the ability of a fixed duration (30 s) tonic GPR stimulation $(5 \mathrm{~Hz})$ to regulate the gastric mill rhythm under both conditions. Extending GPR stimulation through the protractor phase did not introduce an additional complication because stimulating GPR during protraction does not alter LG activity or either phase of the rhythm (DeLong et al., 2009b).

Using tonic GPR stimulation in normal saline, GPR again prolonged the retractor phase (pre-GPR, $8.1 \pm 1.5 \mathrm{~s}$; during GPR, $22.4 \pm 6.7$ s; $n=4 ; p<0.05$ ) without altering the protractor phase duration (pre-GPR, $3.8 \pm 0.9 \mathrm{~s}$; during GPR, $3.4 \pm 0.6 \mathrm{~s} ; n=4 ; p=0.38)$. In contrast, the same tonic GPR stimulation in the presence of CCAP $\left(10^{-7} \mathrm{M}\right)$ did not alter the duration of either the retractor phase (pre-GPR, $10.5 \pm 2.6 \mathrm{~s}$; during GPR, $13.0 \pm 3.6 \mathrm{~s} ; n=4 ; p=0.30)$ or the protractor phase (pre-GPR, $6.3 \pm 0.7 \mathrm{~s}$; during GPR, $6.4 \pm 1.1 \mathrm{~s} ; n=4 ; p=0.47$ ). These results confirmed our model prediction that CCAP gates out the GPR regulation of the gastric mill rhythm.

\section{CCAP gates out the GPR regulation of the gastric mill rhythm by activating $G_{\text {MI-CCAP }}$ in LG}

CCAP excites several gastric mill neurons in addition to LG, including the gastric mill CPG neuron Int1 (Kirby and Nusbaum, 2007). Therefore, although our model predicted that the induction of $G_{\text {MI-CCAP }}$ in LG was sufficient for gating out the GPR effect on the gastric mill rhythm, it remained possible that one or more other CCAP actions contributed to this effect. Consequently, we tested the hypothesis that the CCAP-activated $G_{\mathrm{MI}}$ in LG was necessary and sufficient for gating out this GPR effect. To this end, we first tested the ability of a simulated version of $G_{\mathrm{MI}}$ CCAP, injected into LG using the dynamic clamp, to mimic the bath-applied CCAP regulation of the GPR action on the gastric mill rhythm. For these experiments, we used the same dynamicclamp conductance used previously, which was based on voltageclamp recordings of $I_{\mathrm{MI}-\mathrm{CCAP}}$ in LG (DeLong et al., 2009a).

We compared the effect of GPR stimulation $(5 \mathrm{~Hz})$ under control conditions to the same stimulation during dynamicclamp injection of $G_{\mathrm{MI}-\mathrm{CCAP}}$ in LG. As above, under control conditions the GPR stimulation prolonged retraction (pre-GPR, $6.3 \pm 1.0 \mathrm{~s}$; during GPR, $18.6 \pm 4.7 \mathrm{~s} ; n=5 ; p<0.05$ ) without altering protraction duration (pre-GPR, $5.8 \pm 1.3 \mathrm{~s}$; during GPR, $6.7 \pm 1.2 \mathrm{~s} ; n=5 ; p=0.30$ ) (Fig. $5 A$ ). When the same stimulation was performed while dynamic-clamp $I_{\mathrm{MI}-\mathrm{CCAP}}\left(G_{\mathrm{MI}-\mathrm{CCAP}}, 20 \mathrm{nS}\right)$ was injected into LG, there was no change in the duration of either retraction (pre-GPR, $7.9 \pm 1.5 \mathrm{~s}$; during GPR, $11.0 \pm 2.6 \mathrm{~s} ; n=5$; 
$p=0.17$ ) or protraction (pre-GPR, $8.6 \pm$ 2.2 s; during GPR, $9.0 \pm 2.0 s ; n=5 ; p=$ 0.45 ) (Fig. 5B). These results supported the hypothesis that the presence of $G_{\mathrm{MI}}$ CCAP in LG was sufficient to gate out the GPR influence on the MCN1-elicited gastric mill rhythm.

To test the necessity of $G_{\mathrm{MI}-\mathrm{CCAP}}$ in LG in the aforementioned gating action, we used the dynamic clamp to inject $I_{\mathrm{MI}-\mathrm{CCAP}}$ into LG using a negative conductance version of $G_{\text {MI-CCAP }}(-20$ or $-30 \mathrm{nS})$ during $\operatorname{CCAP}\left(10^{-7} \mathrm{M}\right)$ bath application. This approach is sufficient to eliminate the ability of CCAP to prolong the gastric mill protractor phase (DeLong et al., 2009a). In the absence of this dynamic-clamp manipulation, GPR stimulation $(5-6 \mathrm{~Hz})$ prolonged retraction $(n=5 ; p<0.005)$ without altering protraction duration $(n=5 ; p=0.35)$ during saline superfusion but did not alter the duration of either phase (retraction: $n=5, p=0.16$; protraction: $n=5, p=0.43$ ) during CCAP superfusion (Fig. $6 A, B$ ). In contrast, when $I_{\mathrm{MI}-\mathrm{CCAP}}$ was injected into LG using the negative version of $G_{\mathrm{MI} \text {-CCAP }}$ during CCAP superfusion, GPR stimulation prolonged retraction (pre-GPR, $10.4 \pm 1.9 \mathrm{~s}$; during GPR, $22.5 \pm 1.0 \mathrm{~s} ; n=$ $5 ; p<0.005)$, without altering protraction duration (pre-GPR, $4.7 \pm 0.8 \mathrm{~s}$; during GPR, $4.0 \pm 0.7 s ; n=5 ; p=0.26$ ) (Fig. $6 C)$. The duration of the prolonged retractor phase under these conditions was the same as occurred during saline superfusion (RM-ANOVA, SNK post hoc test, $p=0.90)$. The ability of these dynamicclamp injections with the negative $G_{\text {MI-CCAP }}$ to eliminate the CCAP gating action on the GPR regulation of the gastric mill rhythm supported the hypothesis that the presence of $G_{\text {MI-CCAP }}$ in LG was necessary and sufficient to mediate this CCAP effect.

\section{Discussion}

We have shown that the presence of a peptide hormone weakens or suppresses proprioceptor feedback to a motor circuit. This action occurs despite the fact that the hormone neither influences the proprioceptor synaptic action nor directly alters motor activity during the phase of the motor pattern that is influenced by this proprioceptor. Previous work showed that, during saline superfusion, the proprioceptor neuron GPR selectively prolongs the gastric mill retractor phase by reducing MCN1 release of the peptide transmitter CabTRP Ia (Fig. $7 A, B$ ) (Beenhakker et al., 2005; DeLong et al., 2009b). This action reduces the activation rate of the modulator (MCN1-released CabTRP Ia)-
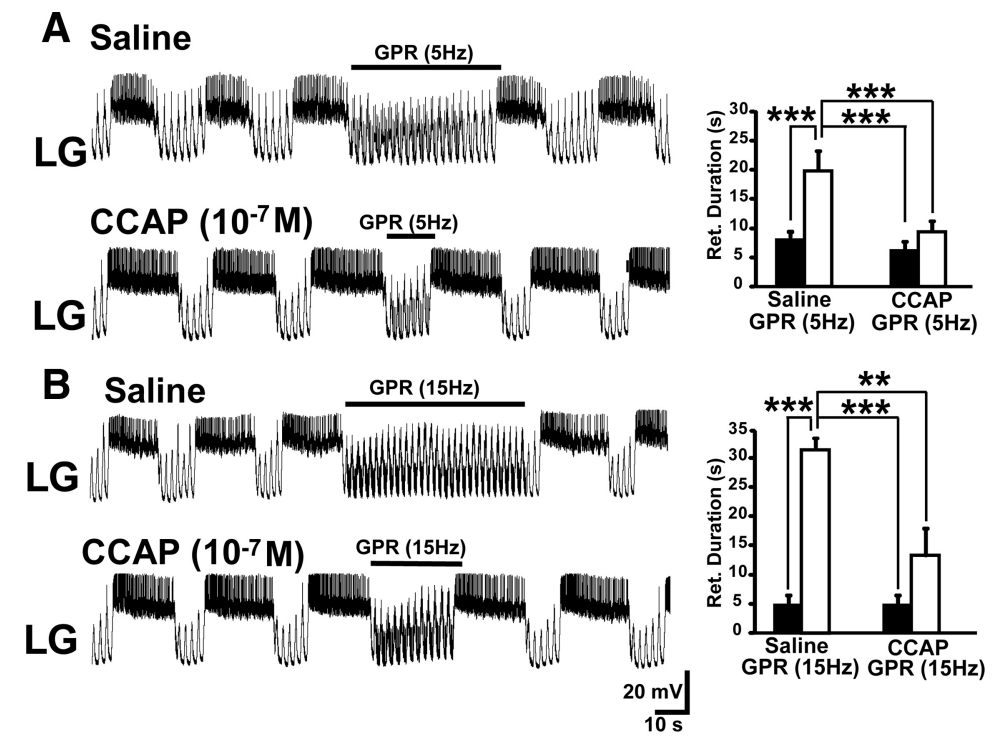

Figure 4. CCAP superfusion reduces the effectiveness of GPR stimulation during the biological MCN1-elicited gastric mill rhythm. $A$, Left, GPR stimulation selectively prolonged retraction (LG silent) under control (saline) conditions during the MCN1gastric mill rhythm. In contrast, the same level of GPR stimulation barely prolonged retraction during CCAP superfusion. Note that, as usual, CCAP prolonged LG burst duration (Kirby and Nusbaum, 2007). Most hyperpolarized $V_{\mathrm{m}}$ : saline, $-62 \mathrm{mV}$; CCAP, $-65 \mathrm{mV}$. Right, Cumulative data showing that GPR consistently prolonged the gastric mill retractor phase during saline superfusion. In contrast, GPR stimulation did not alter retraction duration in the presence of CCAP $\left(10^{-7} \mathrm{M}\right.$; RM-ANOVA, SNK post hoc test, $p=$ $0.32 ; n=5)$. The retraction duration was also prolonged by the GPR stimulation in saline compared with the same stimulation in the presence of CCAP, whereas there was no difference in the duration of this phase during the two control conditions (RM-ANOVA, SNK post hoc test, $p=0.99 ; n=5)$. ${ }^{* *}$ RM-ANOVA, SNK post hoc text, $p<0.001 ; n=5$. The black bars represent gastric mill cycles without GPR stimulation, and the white bars represent cycles with GPR stimulation. Error bars indicate SEM. $\boldsymbol{B}$, Left, Increasing the GPR stimulation frequency prolonged the gastric mill retractor phase in saline but still failed to maintain its effectiveness during CCAP superfusion. Most hyperpolarized $V_{\mathrm{m}}$ : Both panels, $-58 \mathrm{mV}$. Right, Cumulative data showing that increasing the GPR stimulation frequency prolongs the retractor phase during saline superfusion. However, this faster stimulation frequency was not sufficient to overcome the influence of CCAP ( $\left(10^{-7} \mathrm{M}\right)$ (RM-ANOVA, SNK post hoc test, $\left.p=0.13 ; n=3\right)$. Also, as in $\boldsymbol{A}$, the retraction duration was distinct during the GPR stimulations in saline and CCAP, but not during the two control conditions (RM-ANOVA, SNK posthoc test, $p=0.90 ; n=3$ ). ${ }^{* * * R M-A N O V A, ~ S N K ~ p o s t h o c ~ t e s t, ~} p<0.001$; **RM-ANOVA, SNK post hoc test, $p<0.005$. The bars are as above.

A
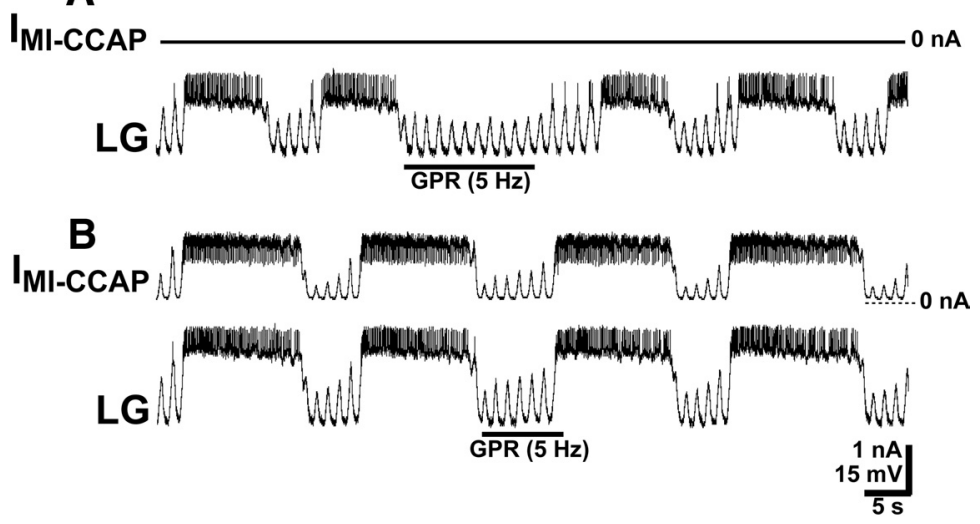

Figure 5. Dynamic-clamp injection of the CCAP-activated current (I MI-CCAP $\left._{\text {- }}\right)$ into LG is sufficient to mimic the ability of bathapplied CCAP to weaken the GPR action on the MCN1-elicited gastric mill rhythm. $\boldsymbol{A}$, In the absence of the dynamic-clamp injection $\left(I_{\mathrm{MI}-\mathrm{CCAP}}, 0 \mathrm{nA}\right), \mathrm{GPR}$ stimulation during the gastric mill retractor phase selectively prolonged that phase. Most hyperpolarized $V_{\mathrm{m}^{\prime}}$ $-59 \mathrm{mV}$. B , Dynamic clamp depolarizing current injection of $I_{\mathrm{MI}-\mathrm{CCAP}}$ into $\mathrm{LG}$ mimicked the ability of bath-applied CCAP to weaken GPR regulation of the gastric mill rhythm. While $I_{\text {MI-CCAP }}$ was being injected into LG, GPR stimulation barely prolonged the retractor

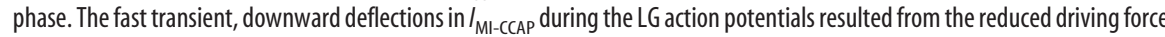

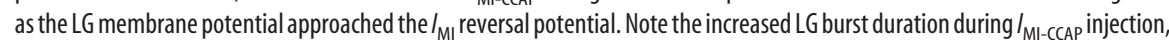
as also occurs during CCAP bath application (Kirby and Nusbaum, 2007). Most hyperpolarized $V_{m^{\prime}}-60 \mathrm{mV}$. Both panels are from the same LG recording. 


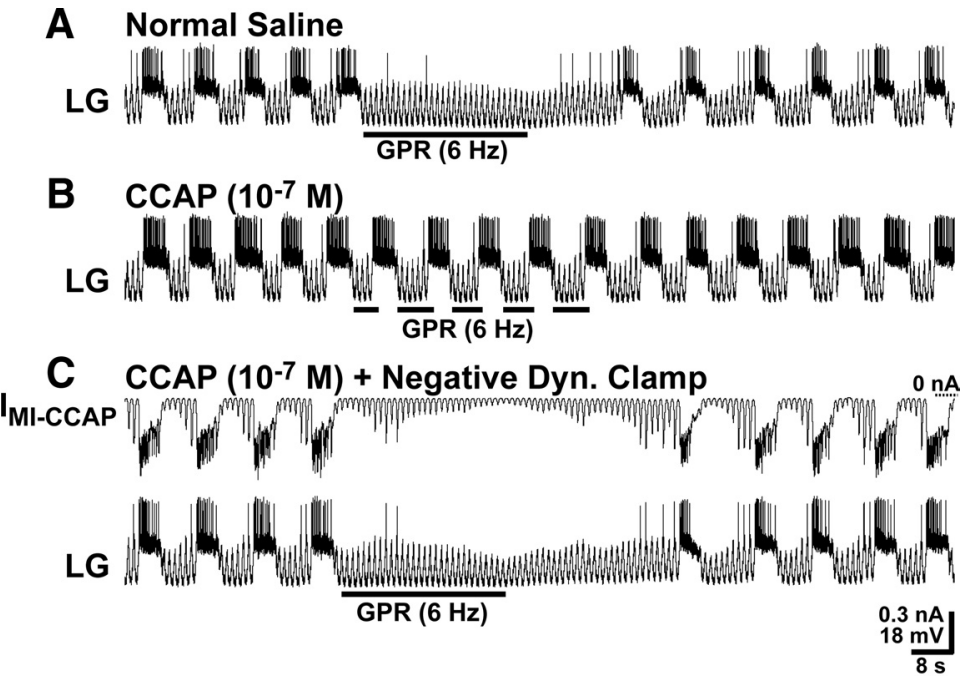

Figure 6. The presence of $G_{\mathrm{MI}-\mathrm{CCAP}_{\mathrm{P}}}$ in $\mathrm{LG}$ is necessary for CCAP to gate out the GPR prolongation of the gastric mill retractor phase. $A$, During saline superfusion, GPR stimulation selectively prolonged the retractor phase of the MCN1- gastric mill rhythm. Most hyperpolarized $V_{\mathrm{m}^{\prime}}-71 \mathrm{mV}$. B, During CCAP superfusion, the effect of GPR stimulation on the retractor phase was gated out, despite stimulating GPR during successive retractor phases. Most hyperpolarized $V_{m^{\prime}}-74 \mathrm{mV}$. C, During CCAP superfusion, dynamic-clamp-mediated injection $I_{\text {MI-CCAP }}$ into $L G$ using a negative version of $G_{\text {MI-cCAP }}$ (note hyperpolarizing current injections) eliminated the ability of CCAP to gate out the GPR action on the MCN1 - gastric mill rhythm. Most hyperpolarized $V_{m^{\prime}}-74 \mathrm{mV}$. All three panels are from the same $L G$ recording.
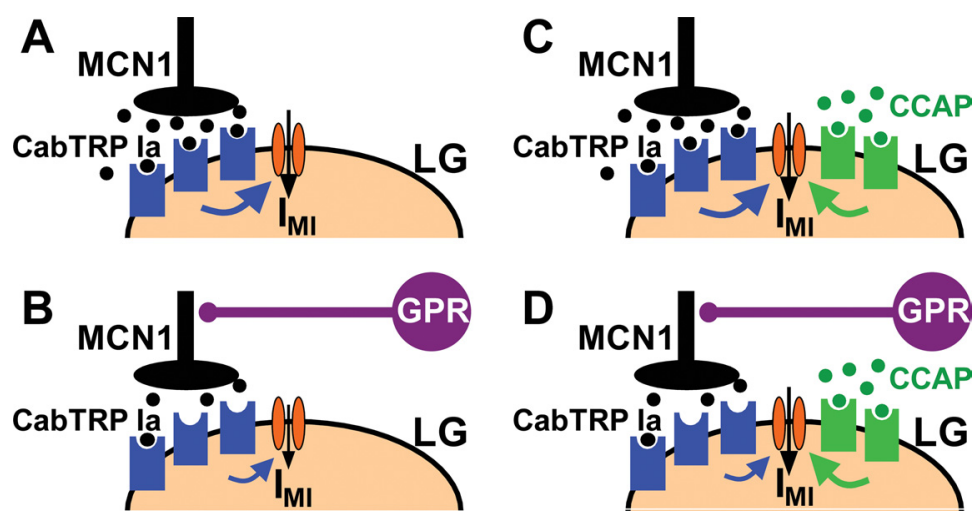

Figure 7. Summary schematic of the mechanism by which CCAP gates out the GPR regulation of the MCN1- gastric mill rhythm. $A$, During the normal gastric mill rhythm retractor phase, with no CCAP present, MCN1 released CabTRP la (filled black circles) binds to receptors on LG (blue geometric shapes) to activate $I_{\mathrm{MI}}$ via an unidentified metabotropic pathway (blue arrow). The downward pointing arrow depicts activated $I_{\mathrm{MI}} \cdot \boldsymbol{B}$, During the gastric mill retractor phase with GPR stimulation and no CCAP present, CabTRP la release from MCN1 is reduced, resulting in a reduced rate of activation of $I_{M \mathrm{MI}}$ (note smaller size of metabotropic- and $I_{\mathrm{MI}}$-associated arrows). C, During the gastric mill retractor phase with (CAP present (filled green circles), $I_{\mathrm{MI}}$ in $\mathrm{LG}$ is coactivated by MCN1-released CabTRP la and bath-applied CCAP. D, During the gastric mill retractor phase with GPR stimulation and CCAP present, GPR still reduces CabTRP Ia release from MCN1. However, because $I_{\text {MI-CCAP }}$ in $\mathrm{GG}$ is not regulated by GPR activity and can compensate for the reduced amount of $I_{\mathrm{MI}-\mathrm{MCN} 1}$, the GPR effect on $I_{\mathrm{MI}}$, and hence on the gastric mill retractor phase, is reduced.

activated inward conductance $G_{\mathrm{MI}-\mathrm{MCN} 1}$ in the gastric mill CPG neuron LG during retraction, thereby slowing the LG neuron escape from Int1-mediated inhibition (Figs. 2, 3). Furthermore, the peptide hormone CCAP selectively prolongs the gastric mill protractor phase via a parallel activation, with MCN1, of $G_{\mathrm{MI}}$ in the LG neuron (Fig. 7C) (Kirby and Nusbaum, 2007; DeLong et al., 2009a).

Our computational model predicted that CCAP gates out the GPR effect on the MCN1-elicited gastric mill rhythm. The model further predicted that this gating effect results specifically from CCAP providing a parallel pathway for activating $G_{\mathrm{MI}}$ in the LG neuron that is MCN1 independent, and therefore not regulated by GPR (Fig. 7D). We verified these model predictions by dem- onstrating that either bath-applied CCAP or dynamic-clamp injection of $G_{\mathrm{MI}-\mathrm{CCAP}}$ into the biological LG neuron gated out the GPR action on the gastric mill rhythm, whereas dynamic-clamp injections using a negative version of $G_{\text {MI-CCAP }}$ into LG during CCAP bath application restored this GPR action. Thus, CCAP-activated $G_{\mathrm{MI}}$ in LG is necessary and sufficient to gate out the sensory feedback action of GPR on the MCN1-elicited gastric mill rhythm.

\section{Modulation of sensory input to a motor circuit}

Sensory neuron activity is often regulated at the level of the sensory transduction apparatus and/or near their axon terminals in the CNS (Birmingham et al., 2003; Bewick et al., 2005; Kohlmeier et al., 2006; Rossignol et al., 2006; Blitz and Nusbaum, 2007; Kindt et al., 2007; Barrière et al., 2008; Glanzman, 2008; Maher and Westbrook, 2008; Pírez and Wachowiak, 2008; Petzold et al., 2009; Rudomin, 2009). Regulation of sensory input also occurs via actions in the postsynaptic targets of the sensory neurons (Edwards et al., 2002; Le Bon-Jego et al., 2006; Glanzman, 2008). Here, we demonstrated that modulation of sensory transmission can also result from a downstream circuit action. Specifically, the peptide hormone CCAP gates out the effect of the proprioceptor neuron GPR, not by a direct action on GPR or on the postsynaptic target (MCN1) by which GPR alters gastric mill CPG output, but by activating a voltage-dependent ionic current in a circuit neuron downstream of the relevant GPR target. This downstream action enables the circuit to compensate for the sensory-mediated reduction in modulatory drive. Insofar as CCAP, as a circulating hormone, also has access to the associated peripheral structures, it remains possible that CCAP additionally modulates this sensorimotor pathway by influencing GPR sensitivity to muscle stretch or spike initiation, as do several other neuromodulators (Birmingham et al., 2003).

\section{Modulating neuronal properties to alter motor circuit sensitivity to sensory feedback}

CCAP alters the modulatory state of the gastric mill CPG without substantially changing the gastric mill motor pattern, even when applied at relatively high concentrations (Kirby and Nusbaum, 2007). This limited influence on motor circuit output results from its convergent activation, with MCN1-released CabTRP Ia, of $G_{\mathrm{MI}}$ in LG (DeLong et al., 2009a). In contrast, modulation frequently causes considerable change in motor circuit output (Marder et al., 2005; Dickinson, 2006; Marder and Bucher, 2007; Doi and Ramirez, 2008). Despite its modest direct effect on the 
gastric mill rhythm, the same CCAP concentrations enable a substantially altered responsiveness to a sensory input.

Our previous work (DeLong et al., 2009a) established that, despite its modest effect on the gastric mill rhythm, CCAP changes the $G_{\mathrm{MI}}$ dynamics in the LG neuron. These altered dynamics not only cause a modest prolongation of protraction but enable the retractor phase to retain its control duration. Both of these effects result from $G_{\mathrm{MI}-\mathrm{CCAP}}$ reducing the impact of synaptic regulation of $G_{\mathrm{MI}}$ by LG inhibition of $\mathrm{MCN1}_{\mathrm{STG}}$ (DeLong et al., 2009a). The same altered dynamics underlie the ability of CCAP to gate out the GPR inhibition of $\mathrm{MCN1}_{\mathrm{STG}}$ during retraction (this study).

The modulatory state of a network can also be altered without affecting network output when a modulator that normally changes network output is present at a low concentration. For example, in the lobster STNS such a latent state change enables the cardiac sac network to become responsive to an otherwise ineffective, second peptide modulator (Dickinson et al., 1997). The mechanism underlying this latter effect has yet to be elucidated, although based on more recent work on crab pyloric circuit neurons, it may be mediated by a convergent activation of $G_{\mathrm{MI}}$ (Swensen and Marder, 2000, 2001). A peptide modulator also strengthens considerably the sole (inhibitory) pyloric circuit feedback synapse to the pyloric pacemaker neurons, yet this enhanced synaptic action does not alter the pyloric cycle frequency (Thirumalai et al., 2006). As is the case for the relative impact of CCAP on the gastric mill rhythm and GPR regulation of this rhythm, this strengthened synaptic feedback may well influence pyloric cycle frequency in the presence of a parallel perturbation.

There is a growing literature demonstrating the ability of neurons to express broadly different levels of intrinsic and synaptic conductances and yet produce conserved neuronal and circuit activity patterns (Cymbalyuk et al., 2002; Prinz et al., 2004; Marder and Goaillard, 2006; Saideman et al., 2007b; Goaillard et al., 2009; Grashow et al., 2009; Olypher and Calabrese, 2009; Taylor et al., 2009). These studies suggest that, although the system output remains stable in the presence of varying intrinsic and synaptic conductances, the differing combinations of conductance levels can make a neuron or network differentially sensitive to a particular perturbation. Our study establishes, in a biological system, that conserved motor output can indeed mask a differential sensitivity to an identified synaptic input. Specifically, although the versions of the gastric mill rhythm in the presence and absence of CCAP are similar, the distinct $G_{\mathrm{MI}}$ dynamics in LG during these two rhythms enable the gastric mill circuit to respond differently to input from GPR. By extension, this study also highlights the care that should be taken when inferring conserved neuronal and circuit properties on the basis of an unchanging or modest change in motor output in the presence of a modulatory action.

We did not explore the full range of CCAP concentrations that influence the GPR action on the gastric mill rhythm. However, the fact that $10^{-9} \mathrm{M}$ CCAP was a consistently effective concentration for gating out this GPR feedback effect suggests that this hormonal action is likely to occur in the intact animal. The steady-state and feeding-related concentration of CCAP circulating in the $C$. borealis hemolymph is not known, but studies in other crabs (Carcinus maenas, Orconectes limosus) suggest that $10^{-9} \mathrm{M}$ CCAP is within the normal range of concentrations that occur during periods of enhanced release (Phlippen et al., 2000) [Kirby and Nusbaum (2007), their Discussion]. One condition in which elevated CCAP levels appear to occur is in food-deprived C. borealis (Chen et al., 2009). The in vivo conditions, however, may have additional degrees of freedom because of both the presence of other circulating hormones and the fact that, although GPR likely provides feedback whenever the gastric mill rhythm is occurring, its firing rate and pattern can be modulated at/near its sensory transduction site (Katz et al., 1989; Birmingham et al., 1999, 2003).

In conclusion, there is growing support for the ability of neuronal ensembles to use a variety of cellular and synaptic properties to generate a relatively stable circuit output. These studies have raised the issue of whether these apparently unchanging outputs maintain a consistent response to perturbations. The present study establishes that this is not necessarily the case, as the regulation of the MCN1-elicited gastric mill rhythm by the proprioceptor neuron GPR is weakened by the presence of the peptide hormone CCAP, despite the fact that CCAP causes only a modest change in one phase of this rhythm and does not change the phase of the rhythm affected by the input from GPR.

\section{References}

Barrière G, Simmers J, Combes D (2008) Multiple mechanisms for integrating proprioceptive inputs that converge on the same motor patterngenerating network. J Neurosci 28:8810-8820.

Bartos M, Nusbaum MP (1997) Intercircuit control of motor pattern modulation by presynaptic inhibition. J Neurosci 17:2247-2256.

Bartos M, Manor Y, Nadim F, Marder E, Nusbaum MP (1999) Coordination of fast and slow rhythmic neuronal circuits. J Neurosci 19:6650-6660.

Beenhakker MP, Nusbaum MP (2004) Mechanosensory activation of a motor circuit by coactivation of two projection neurons. J Neurosci 24:6741-6750.

Beenhakker MP, DeLong ND, Saideman SR, Nadim F, Nusbaum MP (2005) Proprioceptor regulation of motor circuit activity by presynaptic inhibition of a modulatory projection neuron. J Neurosci 25:8794-8806.

Beenhakker MP, Kirby MS, Nusbaum MP (2007) Mechanosensory gating of proprioceptor input to modulatory projection neurons. J Neurosci 27:14308-14316.

Bewick GS, Reid B, Richardson C, Banks RW (2005) Autogenic modulation of mechanoreceptor excitability by glutamate release from synaptic-like vesicles: evidence from the rat muscle spindle primary sensory ending. J Physiol 562:381-394.

Birmingham JT, Szuts ZB, Abbott LF, Marder E (1999) Encoding of muscle movement on two time scales by a sensory neuron that switches between spiking and bursting modes. J Neurophysiol 82:2786-2797.

Birmingham JT, Billimoria CP, DeKlotz TR, Stewart RA, Marder E (2003) Differential and history-dependent modulation of a stretch receptor in the stomatogastric system of the crab, Cancer borealis. J Neurophysiol 90:3608-3616

Blitz DM, Nusbaum MP (2007) Mechanosensory regulation of invertebrate motor systems. In: Invertebrate neurobiology (North G, Greenspan RJ, eds), pp 185-208. Cold Spring Harbor, NY: Cold Spring Harbor Laboratory.

Blitz DM, Christie AE, Coleman MJ, Norris BJ, Marder E, Nusbaum MP (1999) Different proctolin neurons elicit distinct motor patterns from a multifunctional neuronal network. J Neurosci 19:5449-5463.

Büschges A, Akay T, Gabriel JP, Schmidt J (2008) Organizing network action for locomotion: insights from studying insect walking. Brain Res Rev 57:162-171.

Chen R, Ma M, Hui L, Zhang J, Li L (2009) Measurement of neuropeptides in crustacean hemolymph via MALDI mass spectrometry. J Am Soc Mass Spectrom 20:708-718.

Christie AE, Baldwin D, Turrigiano G, Graubard K, Marder E (1995) Immunocytochemical localization of multiple cholecystokinin-like peptides in the stomatogastric nervous system of the crab Cancer borealis. J Exp Biol 198:263-271.

Coleman MJ, Meyrand P, Nusbaum MP (1995) A switch between two modes of synaptic transmission mediated by presynaptic inhibition. Nature 378:502-505.

Cymbalyuk GS, Gaudry Q, Masino MA, Calabrese RL (2002) Bursting in leech heart interneurons: cell-autonomous and network-based mechanisms. J Neurosci 22:10580-10592. 
DeLong ND, Kirby MS, Blitz DM, Nusbaum MP (2009a) Parallel regulation of a modulator-activated current via distinct dynamics underlies comodulation of motor circuit output. J Neurosci 29:12355-12367.

DeLong ND, Beenhakker MP, Nusbaum MP (2009b) Presynaptic inhibition selectively weakens peptidergic cotransmission in a small motor system. J Neurophysiol 102:3492-3504.

Dickinson PS (2006) Neuromodulation of central pattern generators in invertebrates and vertebrates. Curr Opin Neurobiol 16:604-614.

Dickinson PS, Fairfield WP, Hetling JR, Hauptman J (1997) Neurotransmitter interactions in the stomatogastric system of the spiny lobster: one peptide alters the response of a central pattern generator to a second peptide. J Neurophysiol 77:599-610.

Doi A, Ramirez JM (2008) Neuromodulation and the orchestration of the respiratory rhythm. Respir Physiol Neurobiol 164:96-104.

Edwards DH, Yeh SR, Musolf BE, Antonsen BL, Krasne FB (2002) Metamodulation of the crayfish escape circuit. Brain Behav Evol 60:360-369.

Glanzman DL (2008) New tricks for an old slug: the critical role of postsynaptic mechanisms in learning and memory in Aplysia. Prog Brain Res 169:277-292.

Goaillard JM, Taylor AL, Schulz DJ, Marder E (2009) Functional consequences of animal-to-animal variation in circuit parameters. Nat Neurosci 12:1424-1430.

Grashow R, Brookings T, Marder E (2009) Reliable neuromodulation from circuits with variable underlying structure. Proc Natl Acad Sci U S A 106:11742-11746.

Jing J, Weiss KR (2005) Generation of variants of a motor act in a modular and hierarchical motor network. Curr Biol 15:1712-1721.

Katz PS, Harris-Warrick RM (1989) Serotonergic/cholinergic muscle receptor cells in the crab stomatogastric nervous system. II. Rapid nicotinic and prolonged modulatory effects on neurons in the stomatogastric ganglion. J Neurophysiol 62:571-581.

Katz PS, Eigg MH, Harris-Warrick RM (1989) Serotonergic/cholinergic muscle receptor cells in the crab stomatogastric nervous system. I. Identification and characterization of the gastropyloric receptor cells. J Neurophysiol 62:558-570.

Kindt KS, Quast KB, Giles AC, De S, Hendrey D, Nicastro I, Rankin CH, Schafer WR (2007) Dopamine mediates context-dependent modulation of sensory plasticity in C. elegans. Neuron 55:662-676.

Kirby MS, Nusbaum MP (2007) Peptide hormone modulation of a neuronally modulated motor circuit. J Neurophysiol 98:3206-3220.

Kohlmeier KA, Soja PJ, Kristensen MP (2006) Disparate cholinergic currents in rat principal trigeminal sensory nucleus neurons mediated by M1 and $\mathrm{M} 2$ receptors: a possible mechanism for selective gating of afferent sensory neurotransmission. Eur J Neurosci 23:3245-3258.

Le Bon-Jego M, Masante-Roca I, Cattaert D (2006) State-dependent regulation of sensory-motor transmission: role of muscarinic receptors in sensory-motor integration in the crayfish walking system. Eur J Neurosci 23:1283-1300.

Li L, Kelley WP, Billimoria CP, Christie AE, Pulver SR, Sweedler JV, Marder E (2003) Mass spectrometric investigation of the neuropeptide complement and release in the pericardial organs of the crab, Cancer borealis. J Neurochem 87:642-656.

Maher BJ, Westbrook GL (2008) Co-transmission of dopamine and GABA in periglomerular cells. J Neurophysiol 99:1559-1564.

Marder E (1987) Neurotransmitters and neuromodulators. In: The crustacean stomatogastric system (Selverston AI, Moulins M, eds), pp 263-300. Springer: Berlin.

Marder E, Bucher D (2007) Understanding circuit dynamics using the stomatogastric nervous system of lobsters and crabs. Annu Rev Physiol 69:291-316.
Marder E, Goaillard JM (2006) Variability, compensation and homeostasis in neuron and network function. Nat Rev Neurosci 7:563-574.

Marder E, Bucher D, Schulz DJ, Taylor AL (2005) Invertebrate central pattern generation moves along. Curr Biol 15:R685-R699.

McLean DL, Sillar KT (2004) Metamodulation of a spinal locomotor network by nitric oxide. J Neurosci 24:9561-9571.

Nadim F, Manor Y, Nusbaum MP, Marder E (1998) Frequency regulation of a slow rhythm by a fast periodic input. J Neurosci 18:5053-5067.

Nusbaum MP, Beenhakker MP (2002) A small-systems approach to motor pattern generation. Nature 417:343-350.

Nusbaum MP, Blitz DM, Swensen AM, Wood D, Marder E (2001) The roles of cotransmission in neural network modulation. Trends Neurosci 24:146-154.

Olypher AV, Calabrese RL (2009) How does maintenance of network activity depend on endogenous dynamics of isolated neurons? Neural Comput 21:1665-1682.

Pearson KG (2008) Role of sensory feedback in the control of stance duration in walking cats. Brain Res Rev 57:222-227.

Petzold GC, Hagiwara A, Murthy VN (2009) Serotonergic modulation of odor input to the mammalian olfactory bulb. Nat Neurosci 12:784-791.

Phlippen MK, Webster SG, Chung JS, Dircksen H (2000) Ecdysis of decapod crustaceans is associated with a dramatic release of crustacean cardioactive peptide into the haemolymph. J Exp Biol 203:521-536.

Pírez N, Wachowiak M (2008) In vivo modulation of sensory input to the olfactory bulb by tonic and activity-dependent presynaptic inhibition of receptor neurons. J Neurosci 28:6360-6371.

Prinz AA, Bucher D, Marder E (2004) Similar network activity from disparate circuit parameters. Nat Neurosci 7:1345-1352.

Rossignol S, Dubuc R, Gossard JP (2006) Dynamic sensorimotor interactions in locomotion. Physiol Rev 86:89-154.

Rudomin P (2009) In search of lost presynaptic inhibition. Exp Brain Res 196:139-151.

Saideman SR, Ma M, Kutz-Naber KK, Cook A, Torfs P, Schoofs L, Li L, Nusbaum MP (2007a) Modulation of rhythmic motor activity by pyrokinin peptides. J Neurophysiol 97:579-595.

Saideman SR, Blitz DM, Nusbaum MP (2007b) Convergent motor patterns from divergent circuits. J Neurosci 27:6664-6674.

Sharp AA, O’Neil MB, Abbott LF, Marder E (1993) The dynamic clamp: artificial conductances in biological neurons. Trends Neurosci 16:389-394.

Stein W, DeLong ND, Wood DE, Nusbaum MP (2007) Divergent cotransmitter actions underlie motor pattern activation by a modulatory projection neuron. Eur J Neurosci 26:1148-1165.

Swensen AM, Marder E (2000) Multiple peptides converge to activate the same voltage-dependent current in a central pattern-generating circuit. J Neurosci 20:6752-6759.

Swensen AM, Marder E (2001) Modulators with convergent cellular actions elicit distinct circuit outputs. J Neurosci 21:4050-4058.

Taylor AL, Goaillard JM, Marder E (2009) How multiple conductances determine electrophysiological properties in a multicompartment model. J Neurosci 29:5573-5586.

Thirumalai V, Prinz AA, Johnson CD, Marder E (2006) Red pigment concentrating hormone strongly enhances the strength of the feedback to the pyloric rhythm oscillator but has little effect on pyloric rhythm period. J Neurophysiol 95:1762-1770.

Weimann JM, Meyrand P, Marder E (1991) Neurons that form multiple pattern generators: identification and multiple activity patterns of gastric/ pyloric neurons in the crab stomatogastric system. J Neurophysiol 65:111-122.

Wood DE, Stein W, Nusbaum MP (2000) Projection neurons with shared cotransmitters elicit different motor patterns from the same neural circuit. J Neurosci 20:8943-8953. 